ISSN 0081-7147

e-ISSN 2451-1331

\title{
Tłok pieczęci konwentu cystersów z Wągrowca z 1746 r. - nowy nabytek Archiwum Państwowego w Poznaniu. Komunikat
}

\begin{abstract}
Zarys treści: W 1746 r. konwent cystersów z klasztoru w Wągrowcu zamówił nowy tłok pieczęci, w którego polu matrycy znalazł się także nowy herb z wyobrażeniem trzech rzek. W bliżej nieznanych okolicznościach tłok ten trafił w ręce czeskiego właściciela, od którego został odkupiony i w październiku 2020 r. stał się częścią zasobu Archiwum Państwowego w Poznaniu. Artykuł ukazuje kontekst wprowadzenia typariusza do użycia kancelaryjnego, łącząc jego powstanie ze zmianami formalno-prawnych i ekonomicznymi, do których doszło w opactwie po $1745 \mathrm{r}$. Podejmuje także problem relacji między wyobrażonym na pieczęci herbem konwentu a herbem wągrowieckiego opactwa, wskazując na trwałość przyjętych, a wypracowanych w połowie XVIII w. rozwiązań.

Abstract: In 1746, the Cistercians from the monastery at Wagrowiec ordered a new seal matrix, which also included a new coat of arms depicting three rivers. In unknown circumstances, the seal fell into the hands of a Czech owner, from whom it was purchased, and, in October 2020, it became part of the collection of the State Archives in Poznan. The article presents the circumstances of the introduction into the chancellery of the seal matrix, relating its production with the formal, legal, and economic changes which took place at the abbey after 1745. It also addresses the issue of the relationship between the convent's coat of arms depicted on the seal and the coat of arms of the abbey at Wagrowiec, pointing to the durability of the solutions adopted and developed in the middle of the eighteenth century.
\end{abstract}

Słowa kluczowe: sfragistyka, cystersi, Wągrowiec

Keywords: sphragistics, Cistercians, Wągrowiec

Najwięcej zachowanych współcześnie typariuszy z dawnych opactw cysterskich pochodzi z Dolnego Śląska. W Muzeum Narodowym we Wrocławiu znajduje się ich łącznie aż 71, znane są tłoki z opactw w: Henrykowie (7 egzemplarzy), Jemielnicy (6), Kamieńcu Ząbkowickim (4), Krzeszowie (18), Lubiążu (13), Rudach Wielkich (15) oraz cysterek z Trzebnicy (8) ${ }^{1}$. Tłoki pieczęci o cysterskiej proweniencji z obszaru Wielkopolski należą do wyjątkowo rzadkich zabytków. Znane są dwa tłoki pieczęci sądowej

${ }^{1}$ B. Marcisz-Czapla, Tłoki pieczęci i pieczęcie kościelne z terenu Ślaska, w: Gloria Deo. Rzemiosto sakralne, t. 2, red. M. Korżel-Kraśna, Wrocław 2010, s. 98-101, nr 54, 55, 56, 57, 58, 59, 60 (Henryków); s. 101-103, nr 61, 62, 63, 64, 65, 66 (Jemielnica); s. 101-105, nr 68, 69, 70, 71 (Kamieniec Ząbkowicki); s. 105-110, nr 72, 73, 74, 75, 76, 77, 78, 79, 80, 81, 82, 93, 84, 85, 86, 87, 88, 89 (Krzeszów); s. 92-116, nr 92, 93, 94, 95, 96, 97, 98, 99, 100, 101, 102, 103, 104 (Lubiąż); s. 117-122, nr 107, 108, 109, 110, 111, 112, 113, 114, 115, 116, 117. 118, 119, 120, 121 (Rudy Wielkie); s. 123-125, nr 122, $123,124,125,126,127,128,129$ (Trzebnica). 
z Paradyża ${ }^{2}$ oraz typariusz zarządu domeny z Obry $^{3}$. Pod koniec 2020 r. Archiwum Państwowe w Poznaniu nabyło do swoich zasobów tłok z Wągrowca.

Gdy w 2003 r. ukazał się czwarty tom „Studiów i Materiałów do Dziejów Pałuk”, w którym Paweł Stróżyk opublikował artykuł na temat pieczęci konwentu wągrowieckiego, nikt nie zdawał sobie sprawy, że gdzieś w Czechach, w prywatnych rękach, zachował się tłok opisanej tam pieczęci (typ IV)4. Pierwsza informacja w jego sprawie dotarła do dyrektora Archiwum Państwowego w Poznaniu Henryka Krystka 6 VIII 2020 za pośrednictwem Marcina Hlebionka, który przekierował maila otrzymanego w tej sprawie od Karela Müllera, dyrektora Archiwum Ziemskiego w Opawie. K. Müller informował w nim, że istnieje możliwość zakupu tłoka pieczęci konwentu cystersów z Wągrowca od czeskiego właściciela, Pavla Ryjáčka. Odpowiadając na tę ofertę, H. Krystek, po uzyskaniu stosownych opinii eksperckich, w mailu do P. Ryjáčka z 24 VIII 2020 zadeklarował chęć zakupu tłoka i zaakceptował zaproponowane warunki finansowe. Równocześnie rozpoczął rozmowy $\mathrm{z}$ władzami miasta i gminy Wagrowiec w celu uzyskania wsparcia finansowego na zakup obiektu do zasobu Archiwum Państwowego w Poznaniu. Ostatecznie 22 IX 2020 doszło do podpisania umowy zakupu tłoka. Z jednej strony wystąpili wspólnie: Archiwum Państwowe w Poznaniu reprezentujące Skarb Państwa, Gmina Wągrowiec reprezentowana przez wójta gminy oraz gmina miejska Wągrowiec reprezentowana przez burmistrza miasta Wągrowiec, z drugiej strony właściciel tłoka P. Ryjáček. Ostatecznie 28 X 2020 tłok konwentu wągrowieckiego przesyłką kurierską dotarł do AP w Poznaniu5.

Zakupiony typariusz pieczęci ma $134 \mathrm{~mm}$ całkowitej wysokości, jego matryca wykonana jest z mosiądzu i ma średnicę 48,5 mm, wysokość $6 \mathrm{~mm}$, jest wklęsło ryta (zob. il. 1). W polu pieczęci wyobrażono postać Panny Marii w koronie na głowie i z Dzieciątkiem na lewym ręku, którego głowę otacza nimb. Madonna ma długie włosy opadające na plecy. Obie postacie wyobrażono w portalu o formach nawiązujących do renesansu, z kolumnami stojącymi na bazach i zwieńczonych głowicami w typie toskańskiego porządku architektonicznego. Kolumny i łuk wieńczący portal ozdobiono ornamentem roślinnym w formie wici. Pole między kolumnami a wewnętrznym okoleniem pola inskrypcji wypełnia ornament okuciowo-rollwerkowy. Postać Madonny stoi na trójstopniowym podeście, na którym wspierają się również kolumny portalu. Poniżej umieszczono, nawiązującą $\mathrm{w}$ formie do typu renesansowego, tarczę $\mathrm{z}$ herbem $\mathrm{z}$ wyobrażeniem trzech falujących rzek w skos. Po bokach tarczy znajdują się ornamenty okuciowe. Pole inskrypcji od wewnętrznej strony okala otok trójelementowy: ciągły, wieńcowy, ciągły, od strony zewnętrznej jedynie otok wieńcowy. Napis rozpoczyna się w dolnej części pieczęci, w górnej rozdzielony jest lukiem portalu: * SIGILLVM * CONVENTVS * / * VANGROVECENSIS : *. Na rancie matrycy znajdują się dwa znaczniki prawidłowego ustawienia tłoka, większy z nich wykonano jednak w niewłaściwym miejscu. Z tego też względu dodano kolejny - mniejszy znacznik, który wyryto już poprawnie. Tłok ma również mosiężną skuwkę o wysokości $22,5 \mathrm{~mm}$, o nieco innym odcieniu metalu. Na skuwce wygrawerowana jest data: 1746. Górne krawędzie cyfr daty skierowane są ku matrycy tłoka (zob. il. 2). Ozdobnie toczony uchwyt wykonany został z drewna bukowego. Ma on u góry dość dużą, spłaszczoną gałkę średnicy aż $69 \mathrm{~mm}$. Uchwyt nosi liczne ślady mniejszych i większych uszkodzeń i został prawdopodobnie, w bliżej nieokreślonym czasie, oczyszczony w zabrudzeń i przebarwień, nosi też ślady wskazujące na to, że był pierwotnie politurowany, co zapewne uwypuklało słoje i strukturę drewna (zob. il. 3). Data wyryta na skuwce potwierdza chronologię wykonania typariusza i wpisuje się w zmiany formalno-prawne i ekonomiczne, które nastąpiły w klasztorze w latach 1737-17456.

\footnotetext{
2 Tamże, s. 116-117, nr 105, 106.

${ }^{3}$ Zbiór tłoków i stempli pieczętnych w zasobie Archiwum Państwowego w Poznaniu, red. P. Pokora, współpr. M. Hlebionek, Poznań 2015, nr 35.

${ }^{4}$ P. Stróżyk, Pieczęcie cystersów z opactwa w Łeknie-Wagrowcu (cz. I), „Studia i Materiały do Dziejów Pałuk”, 4, 2003, s. 179-202, zwł. s. 184-202.

${ }^{5}$ W tym miejscu pragnę podziękować p. Dyrektorowi Archiwum Państwowego w Poznaniu Henrykowi Krystkowi za udostępnienie całości dokumentacji związanej z okolicznościami zakupu opisywanego tłoka.

${ }^{6} \mathrm{~W}$ tym miejscu pragnę podziękować prof. dr. hab. Andrzejowi M. Wyrwie, który w rozmowie telefonicznej 20 VIII 2020 w kontekście przekazanej mu informacji o możliwości nabycia wągrowieckiego tłoka zwrócił moją uwagę na zachodzące tuż przed 1746 r. istotne zmiany ustrojowo-prawne w klasztorze oraz na konieczność nabycia opisywanego tu typariusza właśnie ze względu na jego związek z tymi zmianami.
} 


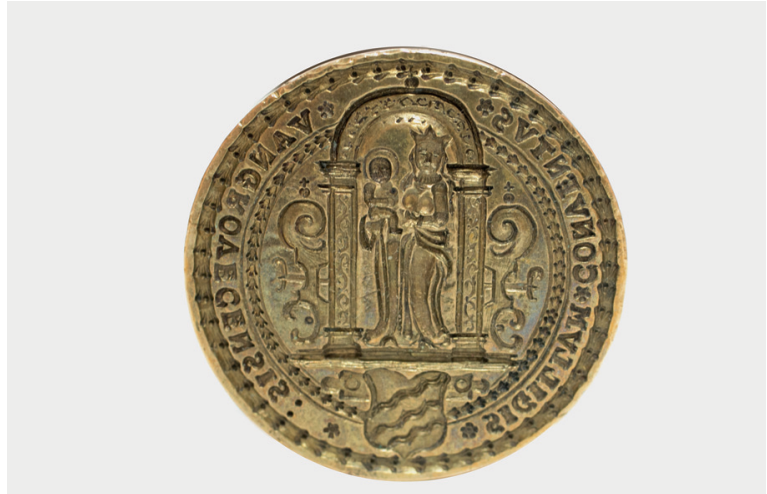

Il. 1. Tłok pieczęci konwentu cystersów z Wągrowca (widok matrycy); AP Poznań, Tłoki pieczęci, sygn. $53 / 983 / 734$

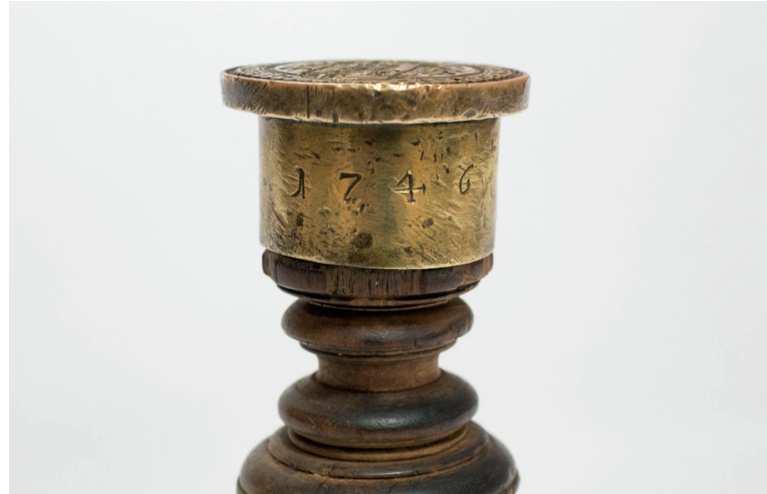

Il. 2. Tłok pieczęci konwentu cystersów z Wągrowca (widok skuwki z wygrawerowaną datą); AP Poznań, Tłoki pieczęci, sygn. 53/983/734

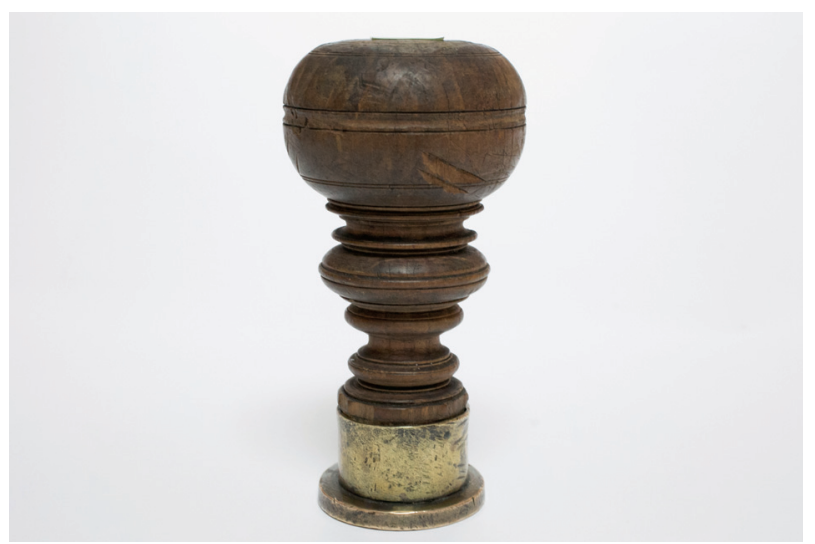

Il. 3. Tłok pieczęci konwentu cystersów z Wągrowca (widok uchwytu); AP Poznań, Tłoki pieczęci, sygn. 53/983/734

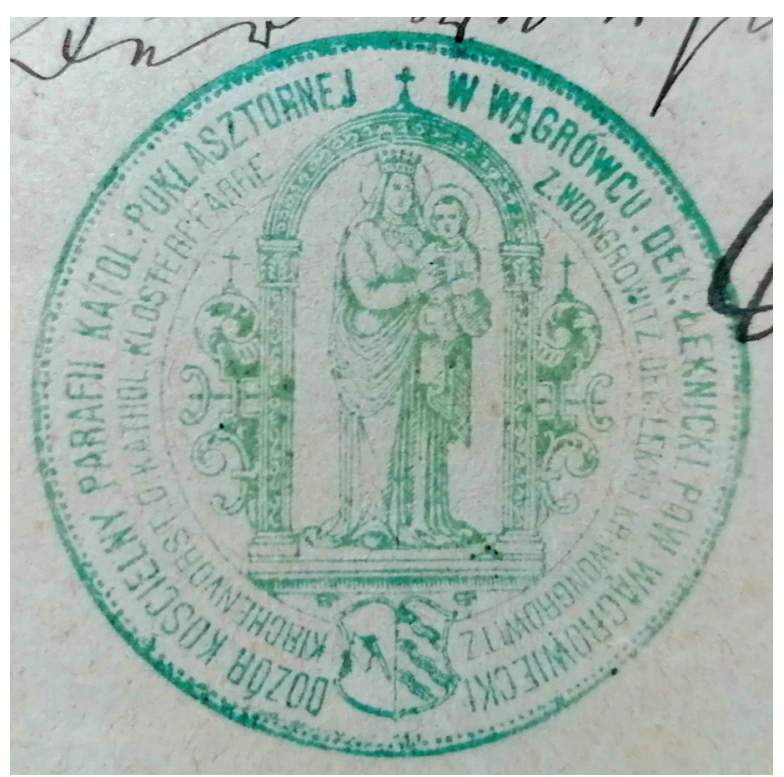

Il. 4. Pieczęć dozoru kościelnego, parafii poklasztornej w Wągrowcu z lat 1877-1891; AA Gniezno, Archiwum Kurii Metropolitalnej, sygn. II 193/1, bpag. (1877)

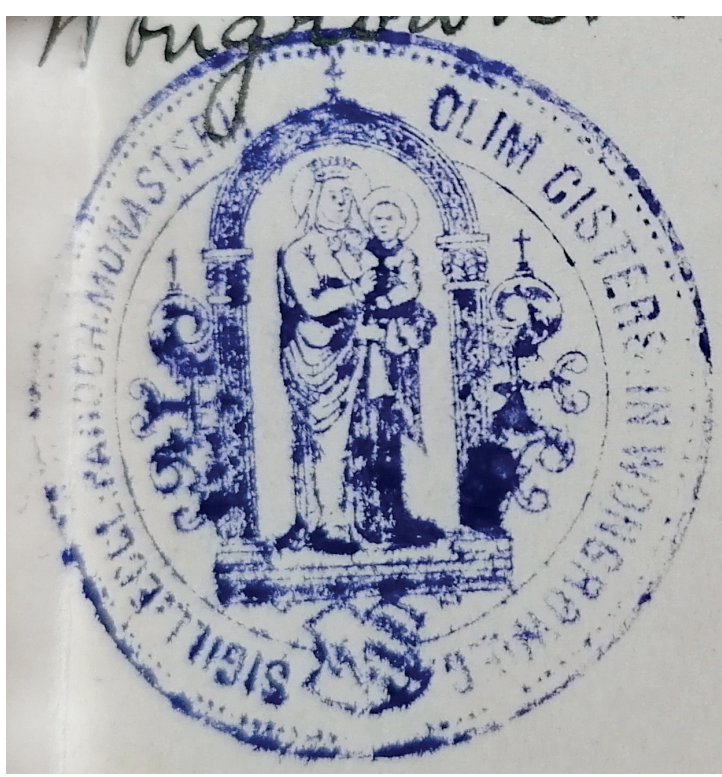

Il. 5. Pieczęć pocysterskiego kościoła parafialnego w Wągrowcu z lat 1890-1901; AA Gniezno, Archiwum Kurii Metropolitalnej, sygn. II 193/1, bpag. (1891) 
Dawne opactwo cystersów w Wągrowcu jest jednym z tych, które posiada obszerną literaturę dotyczącą swoich herbów i pieczęci, w tym pieczęci klasztornego konwentu. Z perspektywy poniższych rozważań dla rozpoznania stanu badań nad pieczęciami konwentu z Wągrowca najistotniejszy jest artykułu P. Stróżyka, w którym autor dokonuje systematyki znanych sobie pieczęci tego zgromadzenia ${ }^{7}$. Wyróżniony przez niego typ IV to pieczęć, co do której ma on wątpliwości związane z datowaniem wprowadzenia jej do kancelaryjnego użytku. Jest to spowodowane złym stanem zachowania odcisku pieczęci przy dokumencie z 31 I $1733^{8}$. Tak pisał: „Trudno stwierdzić, czy jest to ostatni z zachowanych woskowych egzemplarzy typu III, czy też pierwszy dochowany przykład nowej pieczęci konwentu (typ IV), której odcisk wisi obecnie przy dokumencie z 1746 r."”. Wspomniany dokument, wystawiony z datą 31 XI 1746 przez opata Konstantego wraz z przeorem i konwentem, stanowi potwierdzenie nadania straszewskiego młyna dla Michała Lausa ${ }^{10}$. Przy dokumencie wisi, przywieszona jako druga, zachowana w niemal idealnym stanie pieczęć konwentu. Odcisk średnicy 48,5 mm wykonano w wosku czerwonym w misce $\mathrm{z}$ wosku naturalnego w odcieniu żółto-brązowym, a całość znajduje się w metalowej, ozdobnie puncowanej puszcze pieczętnej. Pieczęć przywieszono do dokumentu za pomocą pergaminowego paska. Porównanie zachowanego przy dokumencie odcisku i matrycy opisanego wyżej typariusza prowadzi do wniosku, że został on wykonany tłokiem zakupionym w 2020 r. przez Archiwum Państwowe w Poznaniu. Przy czym, jak zauważa P. Stróżyk, ta właśnie pieczęć konwentu ,poza jednym zasadniczym szczegółem, jest wiernym naśladownictwem [pieczęci - P.P.] typu poprzedniego" "11.

Zdaniem P. Stróżyka: „Fakt ten [wprowadzenia nowej pieczęci konwentu - P.P.] miał miejsce między 1685 a 1746 r. [...] Naszą wiedzę zmienić mogłoby ujawnienie kolejnych odcisków z lat 1685-1746"12. Proponowaną tu, a odnoszącą się do chronologii tej pieczęci sugestię autora można właściwie odrzucić, jednak w dalszej części tego artykułu pojawia się właściwy trop datacji prezentowanej pieczęci. „Zmiany norm prawnych, wynikające z konkordatu [podpisanego w $1737 \mathrm{i}$ wprowadzenia komendy w 1739 - P.P.] [...] zaowocowały przyjęciem w trakcie obrad kapituły prowincjonalnej w klasztorze w Wągrowcu w maju 1744 r. nowych statutów"13 zatwierdzonych przez opata generalnego w kolejnym roku $^{14}$. W innej publikacji poświęconej heraldyce wągrowieckiego opactwa P. Stróżyk powrócił do tego wątku: „Okoliczności wprowadzenia nowego herbu i nowej pieczęci konwentu nie są nam dokładnie znane [...] [konkordat z 1737 - P.P.] rozdzielił instytucję opata komendatoryjnego od wspólnoty mnichów, określając także przypadające stronom części majątku klasztornego. [...] Całkowita samodzielność wspólnoty mnichów oraz ich niezależność od opatów komendatoryjnych mogła uzewnętrznić się w decyzji o sporządzeniu nowego tłoka pieczętnego, różnego od używanego dotychczas oraz przyjęciu nowego herbu konwentu"15. Jestem przekonany, że postawiona przez P. Stróżyka hipoteza dotycząca genezy nowego herbu i nowej pieczęci konwentu jest jak najbardziej zasadna. Wydaje się nie ulegać wątpliwości, że wprowadzenie nowego herbu na nowej pieczęci konwentu wągrowieckiego w $1746 \mathrm{r}$. było jednocześnie kreacją nowego herbu konwentualnego, który w obliczu zaszłych w klasztorze zmian formalno-prawnych i ekonomicznych był formą manifestacji odrębności konwentu od komendatoryjnych opatów. Zapewne na początku 1746 r. zapadła w konwencie wągrowieckim decyzja dotycząca

\footnotetext{
7 P. Stróżyk, Pieczęcie cystersów, s. 184-202.

8 AP Poznań, Cechy m. Wągrowca, sygn. 35.

9 P. Stróżyk, Pieczęcie cystersów, s. 195.

${ }^{10}$ AP Poznań, Cystersi Wągrowiec, sygn. 10.

11 P. Stróżyk, Pieczęcie cystersów, s. 198.

12 Tamże, s. 199.

13 Tamże, s. 200; zob. też A.S. Leski, Statuta Ordinis Cisterciensis, b.m.w., 1745.

${ }^{14} \mathrm{O}$ tych zmianach i wprowadzeniu komendy zob. H. Gapski, Cystersi w Rzeczypospolitej i na Ślasku w XVI-XVIII wieku, w: Monasticon Cisterciense Poloniae, t. 1: Dzieje i kultura męskich klasztorów cysterskich na ziemiach polskich i dawnej Rzeczypospolitej od średniowiecza do czasów nowożytnych, red. A.M. Wyrwa, J. Strzelczyk, K. Kaczmarek, Poznań 1999, s. 55-73, o komendzie: tamże s. 60-63.

15 P. Stróżyk, Heraldyka opactwa cystersów w Łeknie-Wagrowcu, w: Cystersi łekneńscy w krajobrazie kulturowym ziem polskich w 850 lecie fundacji opactwa cysterskiego w Łeknie 1153-2003, red. A.M. Wyrwa, Łekno-Wągrowiec-Poznań 2004, s. 97.
} 
wykonania nowego tłoka pieczęci, którego kancelaryjne użycie potwierdzone jest, jak wyżej wspomniano, po raz pierwszy przy dokumencie z 31 XI $1746^{16}$.

Istotnym elementem odróżniającym omawiany typariusz od wcześniejszej pieczęci konwentu jest fakt wprowadzenia do jego obrazu napieczętnego nowego herbu wyobrażającego w polu tarczy herbowej trzy falujące rzeki w skos. Należy wspomnieć o jeszcze jednym zabytku, na którym znajduje się herb przedstawiający trzy rzeki. Jest to navicula pochodząca z kościoła klasztornego, której sporo uwagi poświęcił P. Stróżyk, odnosząc się do datacji obiektu, a także do umieszczonego na nim herbu i daty: 1718. W konkluzji doszedł on do wniosku, że „umieszczona na łódce data 1718, wykonana techniką puncowania, upamiętnia wykonanie lub pozyskanie dla klasztoru srebrnej łódki, nie zaś moment późniejszego wykonania grawerowanej dekoracji z herbem konwentu i literami CV [Conventus Vangrovecensis - P.P.]. Takie założenie pozwala na utrzymanie w mocy zgłoszonych wcześniej poglądów na temat czasu i okoliczności przyjęcia nowego herbu przez konwent wągrowiecki..."17. Herb z wyobrażeniem trzech rzek znajduje się też na innej mniejszej pieczęci konwentu (typ VI), gdzie towarzyszą mu sygle: $\mathrm{C}$ (onventus) $\mathrm{V}$ (angrovecensis), najwcześniejszy odcisk tej pieczęci znany jest dopiero z $1798^{18}$, a kolejny z 1803 r. ${ }^{19}$ Jak zauważył P. Stróżyk, wyobrażony na tych pieczęciach herb to „nowy herb konwentu lub całego opactwa" ${ }^{20}$. Wydaje się jednak, że jest to za daleko posunięta opinia i uznać należy, że herb z wyobrażeniem trzech rzek w skos, wprowadzony na pieczęć konwentu w 1746 r., to wyłącznie herb konwentu, a nie całego opactwa.

Nasuwa się zatem pytanie, jak wyglądał nowy herb całego opactwa. Odpowiedź daje, jak sądzę, odkryta w 1975 r. „w czasie remontu klasztoru w Wągrowcu na jednej z wież [tarcza, na której - P.P.] widać Topór herb rodu Pałuków, oraz najprawdopodobniej schematycznie przedstawione rzeki Wełnę, Nielbę i Strugę Gołaniecką"21. W publikacji poświęconej heraldyce opactwa w Wągrowcu P. Stróżyk uznał jednak, że „traktując zaś [opisany tu - P.P.] herb jako łączony a więc taki, którego elementy tworzą nowy znak heraldyczny, nie można wykluczyć, że mamy tu do czynienia z nowym herbem opactwa, powstałym z połączenia starszego herbu opactwa (herbu Topór) z nowym herbem konwentu (trzy rzeki), widniejącym [...] na dużej i małej pieczęci [konwentu - P.P.] używanej w XVIII w."22.

Nie ulega wątpliwości, że opisany herb łączony, który można uznać za nowy herb całego opactwa, zadomowił się na dłużej w heraldyce klasztoru i kościoła. W innej formie niż na odnalezionej w $1975 \mathrm{r}$. płytce (bez hełmu i bez labrów) znajduje się na wykonanej w XIX w. pieczęci dozoru kościelnego kościoła poklasztornego, która jest wielokrotnie potwierdzona w użyciu w aktach z lat 1877-189123. Pieczęć ta, średnicy $38 \mathrm{~mm}$, ikonograficznie odwołuje się do pieczęci konwentu wągrowieckiego, jednak poniżej portalu w miejscu tarczy z herbem Topór (P. Stróżyk - typ III) lub herbem z trzema rzekami (P. Stróżyk - typ IV)

16 AP Poznań, Cystersi Wągrowiec, sygn. 10.

17 P. Stróżyk, Uzupetnienie do heraldyki opactwa cystersów w Leknie-Wagrowcu, „Studia i Materiały do Dziejów Pałuk”, 6, 2006, s. 261-265.

18 AP Poznań, Cystersi Wągrowiec, sygn. 35, k. 14.

19 AP Poznań, Cystersi Wągrowiec, sygn. 42, k. 12; o pieczęci tej wspomina też P. Stróżyk, Pieczęcie cystersów, s. 199-200, ryc. 23, 24.

20 P. Stróżyk, Pieczęcie cystersów, s. 200; zob. też tenże, Heraldyka opactwa, s. 97-98.

${ }^{21}$ B. Piechowiak, Herb Wagrowca, „Wielkopolska. Kwartalnik Krajoznawczo-Turystyczny”, 9, 1991, nr 28, s. 16 - autor napisał, że tarcza była kolista, jednak w rzeczywistości ma kształt prostokątny i jest dzielona w słup. W polu pierwszym wyobraża godło herbu Topór, w drugim trzy rzeki w skos. Nad tarczą znajduje się hełm, a otaczają ją labry. Wizerunek tego herbu zob. Translokacja opactwa z Łekna do Wagrowca, red. A.M. Wyrwa, Wągrowiec 1998 (fot. na okładce oraz na s. 4); P. Stróżyk, Heraldyka opactwa, s. 103, tabl. II, nr 6. Czy rzeczywiście herb z wyobrażeniem trzech rzek ma charakter topograficzny? P. Stróżyk nie wyklucza takiej ewentualności (tenże, Pieczęcie cystersów, s. 200). Z kolei M. Adamczewski napisał, że „linie faliste, symbolizują trzy rzeki” (tenże, Heraldyka miast wielkopolskich do końca XVIII wieku, Warszawa 2000, s. 143), wyrażając wątpliwość, czy wspomnianą „tabliczkę wiązać z heraldyką miejską”. Topograficznej genezy godła przedstawiającego trzy rzeki jest natomiast pewien A.M. Wyrwa (potwierdził to w rozmowie telefonicznej odbytej z piszącym te słowa 21 I 2021).

22 P. Stróżyk, Heraldyka opactwa, s. 97-98.

${ }^{23}$ AA Gniezno, Archiwum Kurii Metropolitalnej, sygn. II 193/1, Kasa kościoła parafialnego w Wągrowcu 1879-1892, bpag., odciski tuszowe z lat: 1877, 1878 [4 odciski], 1880, 1883, 1888, 1889, 1890, 1891 [2 odciski], 1892. 
znajduje się tarcza dzielona w słup, w jej polu pierwszym wyobrażone jest godło herbu Topór, a w polu drugim trzy rzeki w skos. Napis w otoku, w języku polskim i niemieckim, w dwóch równoległych wierszach rozdzielonych w górnej części architekturą portalu, brzmi: DOZÓR KOŚCIELNY PARAFII KATOL(ickiej): POKLASZTORNEJ / W WĄGROWCU. DEK(anat): ŁEKNICKI. POW(iat): WĄGROWIECKI // KIRCHENVORST(and). D(er). KATHOL(ischen). KLOSTERPFARRE / Z(u). WONGROWITZ. DEC(anat): LEKNO KR(eis): WONGROWITZ (zob. il. 4).

Podobnie jak w przypadku herbu na pieczęci dozoru kościelnego wygląda kwestia herbu na innej pieczęci pochodzącej z mniej więcej tego samego okresu. Jest to pieczęć poklasztornego kościoła parafialnego w Wągrowcu, średnicy $33 \mathrm{~mm}$, potwierdzona w użyciu w latach 1890-190124. W jej wyobrażeniu, podobnie jak w przypadku pieczęci dozoru kościelnego, nie tylko nawiązano do ikonografii dawnych pieczęci klasztornego konwentu, ale także umieszczono tarczę dzieloną w słup z godłem herbu Topór w polu pierwszym i trzema rzekami w skos w polu drugim. Napis w otoku, w języku łacińskim, w górnej części rozdzielony architekturą portalu, brzmi: SIGILL(um) : ECCL(esiae) : PAROCH(ialis) : MONASTERII / OLIM CISTER(ciensi)S : IN WONGROWIEC (zob. il. 5).

Opisane tu pieczęcie z herbem wyobrażającym tarczę dzieloną w słup świadczą o trwałości herbu konwentualnego wprowadzonego na pieczęci (typ IV), której tłok pochodzi z 1746 r. Podkreślić też należy, że zakupiony do zasobu Archiwum Państwowego w Poznaniu typariusz stanowi wyjątkowo cenny nabytek, gdyż konwentualne/klasztorne tłoki pieczętne z obszaru historycznej Wielkopolski należą do wyjątkowo rzadkich i są obiektami poszukiwanymi oraz wielce pożądanymi przez kolekcjonerów. Tym bardziej zatem należy się cieszyć, że wągrowiecki typariusz trafił do zbiorów publicznych i będzie dostępny dla szerokiego grona naukowców.

\title{
The seal matrix of the Cistercian convent at Wagrowiec from 1746 - A new acquisition of the State Archive in Poznań. A Communiqué
}

\begin{abstract}
Summary: After the formal, legal and economic changes took place at the Cistercian abbey at Wagrowiec in the first half of the eighteenth century, in 1746, the convent ordered a new seal matrix, which also included a new coat of arms depicting three rivers. By a fortunate twist of fate, this seal has survived to the present day, and in October 2020, it was purchased by the State Archives in Poznan. The introduction of this seal matrix into the abbey chancellery is obviously related to the changes described above and the establishment of the office of commendatory abbot at the abbey. The introduction of the new seal resulted in changes in the relationship between the new coat of arms of the convent depicted in the matrix and the coat of arms of the abbey at Wagrowiec. The durability of the coat of arms adopted at that time is indicated, among other things, by the seals of the Church supervision and the post-Cistercian church in Wagrowiec from the nineteenth and twentieth centuries, which bear combined coats of arms and also the three rivers introduced into the abbey heraldry in 1746 . The seal bought for the collection of the State Archives in Poznan is an exceptionally valuable purchase, as the conventual/monastic seals from the area of historical Greater Poland are exceptionally rare monuments of artistic craftsmanship.
\end{abstract}

Nota o Autorze: Piotr Pokora, prof. UAM dr hab., pracownik Wydziału Historii Uniwersytetu im. Adama Mickiewicza w Poznaniu. Zainteresowania badawcze koncentrują się na szeroko pojętych naukach pomocniczych historii ze szczególnym uwzględnieniem, bibliologii historycznej, sfragistyki i heraldyki.

Author: Piotr Pokora, Professor of the Adam Mickiewicz University in Poznań. His research interests focus on broadly understood auxiliary sciences of history with particular emphasis on historical bibliology, sphragistics, and heraldry.

Wydział Historii Uniwersytet im. Adama Mickiewicza w Poznaniu
ul. Uniwersytetu Poznańskiego 7
61-614 Poznań
e-mail: piotrpokora@hotmail.com

${ }^{24}$ Tamże, bpag., odciski tuszowe z lat 1890 i 1891. 


\section{Bibliografia}

Adamczewski M., Heraldyka miast wielkopolskich do końca XVIII wieku, Warszawa 2000

Gapski H., Cystersi w Rzeczypospolitej i na Ślasku w XVI-XVIII wieku, w: Monasticon Cisterciense Poloniae, t. 1: Dzieje i kultura męskich klasztorów cysterskich na ziemiach polskich i dawnej Rzeczypospolitej od średniowiecza do czasów nowożytnych, red. A.M. Wyrwa, J. Strzelczyk, K. Kaczmarek, Poznań 1999, s. 55-73

Marcisz-Czapla B., Tłoki pieczęci i pieczęcie kościelne z terenu Ślaska, w: Gloria Deo. Rzemiosto sakralne, t. 2, red. M. Korżel-Kraśna, Wrocław 2010, s. 92-210

Piechowiak B., Herb Wagrowca, „Wielkopolska. Kwartalnik Krajoznawczo-Turystyczny”, 9, 1991, nr 28, s. 16

Stróżyk P., Heraldyka opactwa cystersów w Łeknie-Wagrowcu, w: Cystersi tekneńscy w krajobrazie kulturowym ziem polskich $w 850$ lecie fundacji opactwa cysterskiego w Leknie 1153-2003, red. A.M. Wyrwa, Lekno-Wągrowiec-Poznań 2004, s. 89-104

Stróżyk P., Pieczęcie cystersów z opactwa w Łeknie-Wagrowcu (cz. I), „Studia i Materiały do Dziejów Pałuk”, 4, 2003, s. 179-202

Stróżyk P., Uzupetnienie do heraldyki opactwa cystersów w Łeknie-Wagrowcu, „Studia i Materiały do Dziejów Pałuk", 6, 2006, s. 261-265

Translokacja opactwa z Łekna do Wagrowca, red. A.M. Wyrwa, Wągrowiec 1998

Zbiór tloków i stempli pieczętnych w zasobie Archiwum Państwowego w Poznaniu, red. P. Pokora, współpr. M. Hlebionek, Poznań 2015 